\title{
Educação Ambiental e Química Ambiental uma proposta de curso de extensão
}

Empowering Educators in Environmental Concepts of Chemical Technology

\section{Introdução}

\section{Educação Ambiental}

A Educação Ambiental (EA) é um processo de educação política que possibilita a aquisição de conhecimentos e habilidades, bem como a formação de atitudes que se transformam necessariamente em práticas de cidadania, com a finalidade de garantir uma sociedade sustentável. Tem-se como objetivo informar e sensibilizar as pessoas e a sociedade em geral sobre a necessidade da adoção de práticas que contribuam para a preservação ambiental ${ }^{1}$.

A prática da EA exige o trabalho pedagógico em três níveis: o Informacional que relaciona o reconhecimento racional e cultural acumulado; o Reflexivo Crítico, que é o autoconhecimento com capacidade de ver e julgar; e a Ação, prática com demonstração de responsabilidade e de consciência dos seus efeitos provocados a nível pessoal e coletivo. Deste modo, a formação de educadores ambientais precisa ser avaliada e debatida a fim de se buscar melhor capacitação e informações atualizadas nesse campo, procurando integrá-los a uma reflexão crítica, que está voltada a uma proposta de ação e intervenção social e política, no sentido de atuar em prol de um ambiente adequado às futuras gerações. $\mathrm{O}$ educador ambiental é, portanto, um profissional de formação interdisciplinar. Essa formação precisa ser compreendida mais profundamente para que, por conseguinte, possa ser sistematizada, melhor desenvolvida e atualizada ${ }^{2}$. Um dos grandes problemas relacionados à formação e ou à educação de profissionais de acordo com os pressupostos de uma Educação Ambiental emancipatória vem sendo a discussão de como desenvolver progra-
Denise Celeste G. de Andrade Rodrigues' e Elaine Ferreira Tôrres ${ }^{2}$

\section{Resumo}

O presente trabalho pretende relatar ações de ampliação de um curso de extensão que une Tecnologia Química e Educação Ambiental, oferecido anualmente aos professores da educação básica e superior e a profissionais que atuam no campo ambiental, a fim de que sejam ressaltados os conceitos pertinentes ao meio ambiente. A metodologia usada na concepção e na ampliação do curso foi baseada em questionários de satisfação aplicados aos participantes, os quais foram realizados sem identificação do aluno. Como resultado, o curso passou de 30 para $78 \mathrm{~h} /$ aula. Podemos concluir que o curso atende à demanda da região e tem contribuído na qualificação e formação continuada de diversos profissionais, uma vez que os egressos atuam em órgãos de meio ambiente e núcleos de educação ambiental local.

Palavras-chaves: Educação Ambiental; Sustentabilidade; Capacitação

Área Temática: Meio Ambiente Linha de Extensão: Educação Profissional 
mas e/ou cursos de diferentes níveis, em espaços formais, que possibilitem a construção de conhecimento em ambientes de aprendizagem dialógicos e solidários, a partir de propostas educacionais que promovam a participação, a autonomia e a emancipação dos educandos. A educação e ou a formação de profissionais que compreendam o papel do educador e os problemas inerentes ao meio ambiente é condição necessária para a consolidação de uma proposta alternativa de Sociedade. A capacitação técnica aliada ao compromisso ético são fundamentais para o alcance de tal objetivo ${ }^{3}$.

Os cursos de EA oferecidos no Estado do Rio de Janeiro, tanto por instituições públicas UFF, CEDERJ, UFRJ, UFFRJ - quanto por Instituições, particulares - SENAC, PUC-RJ, MSB (Centro Universitário Moacyr Sreder Bastos), UGB (Centro Universitário Geraldo Di Biase), Unifeso (Centro universitário Serra dos Órgãos), Faculdades Integradas Simonsen, FEUC (Fundação Educacional Unificada Campograndense) - entre outras, nos níveis de cursos de atualização, aperfeiçoamento, lato sensu ou stricto sensu, presencial ou à distância, abordam a temática em contextos escolares; preservação, conservação e gestão ambiental; diversidade cultural; conceitos de geografia, saúde, sociologia e ecologia, em uma visão transdisciplinar, com o objetivo de formar educadores ambientais, que contribuam para a superação da cultura antropocêntrica, individualista e consumista.

Segundo Silva ${ }^{4}$, os educadores evidenciam a necessidade de o aluno adquirir um conhecimento mínimo de química para poder participar com maior fundamentação na sociedade atual. As transformações que vêm ocorrendo nos métodos de produção, as questões de impacto, a preocupação social com a preservação dos recursos, tudo isso vem exigindo que metodologias voltadas à formação para o meio ambiente sejam implementadas, nos mais diversos cursos, mostrando que a Química e o Meio Ambiente não são compartimentos separados e sim uma unidade.

A Química Ambiental é uma das áreas da ciência que mais tem crescido nas últimas décadas e definida de diversas formas. Como o estudo das origens, do transporte e dos efeitos de espécies químicas na água, no solo e no ar, suas características naturais ou causadas pelo homem, que comprometem a saúde humana e do planeta, procurando entender as interações complexas entre esses sistemas, quais são as suas consequências, de forma a apresentar soluções para a prevenção e correção de problemas ambientais.

Para outros, a Química Ambiental se refere à química dos processos naturais no ar, na água e no solo e aborda o tratamento da poluição. Uma definição atual confere à Química do Meio Ambiente o conceito de Química Verde .

Utilizando os conceitos e definições de Química Ambiental o referido curso é desenvolvido com o objetivo de o educador ambiental, de várias áreas de formação profissional, entender a composição química relacionada ao solo, à água e ao ar, considerando as interações complexas entre esses sistemas, atentos aos conceitos de sustentabilidade e da legislação ambiental.

Ressalta-se que o curso faz parte do projeto de extensão, cadastrado na Sub-Reitoria de Extensão e Cultura (SR3) da UERJ, "Capacitação da Comunidade Local em Meio Ambiente" do Departamento de Química Ambiental da Faculdade de Tecnologia do Campus Regional de Resende.

O campus é situado no eixo Rio-São Paulo em uma região estratégica atualmente chamada de $\mathrm{ABC}$ fluminense, pois é uma área industrial de atividades metal-mecânicas muito próspera economicamente e com vários campos de estudos.

Diante do exposto, o presente trabalho pretende relatar as modificações realizadas na estrutura de um curso de Educação Ambiental, de modo a atender à demanda da região em capacitação ambiental.

\section{Metodologia}

A metodologia adotada na concepção da matriz curricular do curso baseou-se inicialmente em pesquisa de mercado acerca de cursos semelhantes, disponíveis no estado e regiões vizinhas. Além disso, procurou-se, baseado na experiência profissional dos autores, propor temas de atualização para profissionais que atuam como educadores profissionais ou pretendem passar a atuar.

A matriz do curso foi ampliada a cada ano, baseada em questionário de satisfação aplicado ao 
final das aulas sem a identificação do aluno. Também utilizou-se a metodologia do Espaço Aberto como ferramenta de ratificação de opinião.

Durante a realização do curso são realizadas aulas presenciais formais com professores especialistas nas respectivas áreas, aulas práticas no laboratório de química e oficinas. Estas atividades estão inseridas no conteúdo formal do curso; contudo, caminhadas ecológicas e visitas técnicas incluem-se na parte opcional.

Ao final do curso os alunos são avaliados através de prova objetiva, contendo questões abrangentes e pela participação e assiduidade às aulas.

\section{Resultados}

O curso de Educação Ambiental da Faculdade de Tecnologia foi concebido inicialmente no ano de 2008, com carga horária teórica de 30 h/aula e com o objetivo de se difundir conhecimentos de Educação Ambiental e Química Ambiental. Desta forma tornou-se possível a quem queira atuar como educador ambiental compreender conceitos relevantes e difundi-los em sua comunidade.

Ao final da primeira versão do curso, por meio de um questionário de satisfação, os participantes sugeriram aumentar a carga horária e acrescentar aulas práticas. Assim sendo, em 2009, a carga horária foi ampliada para $45 \mathrm{~h} /$ aula e houve acréscimo de aulas práticas. No ano seguinte, aumentou-se a duração para 60 h/aula.

Após nova avaliação chegou-se ao formato atual do curso de 78 horas, com a inserção de oficinas práticas de EA, que foi apontado pelos frequentadores do curso como item importante para a prática profissional. $\mathrm{O}$ conteúdo programático atual é mostrado nos Quadros 1, 2 e 3:

Quadro I: Conteúdo Programático do Curso de EA - Sala de Aula

\begin{tabular}{|c|c|c|}
\hline Unidade & Conteúdo & $\begin{array}{l}\text { Carga } \\
\text { Horária }\end{array}$ \\
\hline $\begin{array}{l}\text { I - Natureza e sociedade } \\
\text { - Cronologia }\end{array}$ & $\begin{array}{l}\text { A evolução da vida no planeta e o surgimento do homem } \\
\text { A evolução cultural do ser humano } \\
\text { As revoluções científicas e o início da Idade Moderna } \\
\text { A Revolução Industrial e a subordinação da natureza } \\
\text { Das sociedades industriais à crítica ecológica das sociedades pós-modernas }\end{array}$ & $4 \mathrm{~h}$ \\
\hline $\begin{array}{l}\text { II - Ambiente Natural } \\
\text { - Biodiversidade e sócio- } \\
\text { diversidade }\end{array}$ & $\begin{array}{l}\text { Os grandes biomas da Terra } \\
\text { Os biomas brasileiros }\end{array}$ & $2 \mathrm{~h}$ \\
\hline $\begin{array}{l}\text { III - Meio Ambiente e } \\
\text { Cidadania }\end{array}$ & $\begin{array}{l}\text { A questão populacional } \\
\text { O meio ambiente urbano e rural } \\
\text { A qualidade de vida } \\
\text { Capacidade de suporte, espaço ambiental e a pegada ecológica sobre o } \\
\text { planeta } \\
\text { Cidadania ambiental }\end{array}$ & $2 \mathrm{~h}$ \\
\hline IV - Atmosfera & $\begin{array}{l}\text { Formação do aerossol atmosférico e das nuvens } \\
\text { Função das nuvens na química troposférica } \\
\text { Características físicas das partículas } \\
\text { Conversão gás-partícula } \\
\text { Reações ácido-base no aerossol atmosférico } \\
\text { Processo de remoção associado ao aerossol } \\
\text { Solubilidade de gases em gotas } \\
\text { Reações aquosas }\end{array}$ & $4 \mathrm{~h}$ \\
\hline V - Poluição Atmosférica & $\begin{array}{l}\text { Processos químicos na atmosfera } \\
\text { Fontes de Poluição Atmosférica } \\
\text { Poluição Urbana } \\
\text { Tipos de Poluentes } \\
\text { Chuva Ácida } \\
\text { Camada de Ozônio } \\
\text { Efeito Estufa }\end{array}$ & $8 \mathrm{~h}$ \\
\hline
\end{tabular}




\begin{tabular}{|c|c|c|}
\hline VI - Poluição Hídrica & $\begin{array}{l}\text { Hidrosfera - água doce e a água do mar } \\
\text { Processos químicos envolvidos no meio aquático } \\
\text { Toxicologia Ambiental } \\
\text { Parâmetros de potabilidade da água Tratamento de água } \\
\text { DQO e DBO }\end{array}$ & $8 \mathrm{~h}$ \\
\hline VII - Poluiçãa de Solos & $\begin{array}{l}\text { Poluição de Solos } \\
\text { Constituintes e propriedades } \\
\text { Mecanismos da interação de poluentes químicos com o meio terrestre } \\
\text { Fontes de contaminação terrestre } \\
\text { Fertilizantes } \\
\text { Defensivos agrícolas } \\
\text { Aterros sanitários }\end{array}$ & $4 \mathrm{~h}$ \\
\hline VIII - Sustentabilidade & $\begin{array}{l}\text { Reciclagem } \\
\text { Racionalização de recursos naturais } \\
\text { Carbono Neutro } \\
\text { Biorremediação } \\
\text { Química Verde }\end{array}$ & $8 \mathrm{~h}$ \\
\hline IX - Reúso de Águas & $\begin{array}{l}\text { Aproveitamento e Reúso de Águas na Indústria } \\
\text { Terminologia } \\
\text { Produção mais Limpa } \\
\text { Técnica dos } 3 \text { R's } \\
\text { Classificação do Reúso de Águas } \\
\text { Consumo de Água na Indústria } \\
\text { Reúso de Água para Abastecimento Industrial } \\
\text { Sistemas de Utilidades } \\
\text { Reúso de Águas em Caldeiras } \\
\text { Reúso de Águas em Torres de Resfriamento Aproveitamento de águas pluviais } \\
\text { Reúso de águas servidas em prédios residenciais, hotéis e escolas }\end{array}$ & $8 \mathrm{~h}$ \\
\hline $\begin{array}{l}\text { X - Impacto da Indústria } \\
\text { de Petróleo e Gás }\end{array}$ & $\begin{array}{l}\text { Prospecção } \\
\text { Exploração } \\
\text { Refino } \\
\text { Transporte } \\
\text { Química e Derivados }\end{array}$ & $8 \mathrm{~h}$ \\
\hline \multirow[t]{2}{*}{ XI - Biocombustíveis } & $\begin{array}{l}\text { Definição } \\
\text { Etanol } \\
\text { Biodiesel } \\
\text { Biogás }\end{array}$ & $4 \mathrm{~h}$ \\
\hline & TOTAL & $60 \mathrm{~h}$ \\
\hline
\end{tabular}

Quadro 2: Conteúdo Programático do Curso de EA - Aulas de Laboratório

\begin{tabular}{l|l|c}
\hline Aula & Objetivo & $\begin{array}{c}\text { Carga } \\
\text { Horária }\end{array}$ \\
\hline 1 - Análise Microbiológica de Água & Análise de coliformes. & $1 \mathrm{~h}$ \\
\hline 2 - Demanda de Cloro & $\begin{array}{l}\text { Avaliar a quantidade de cloro demandada para a produção de } \\
\text { água potável. }\end{array}$ & $1 \mathrm{~h}$ \\
\hline $3-\mathrm{pH}$ e Alcalinidade & $\begin{array}{l}\text { Determinar a acidez, basicidade ou ainda a presenças de íon } \\
\text { hidróxio, carbonato e bicarbonato na amostra de água, parâmetos } \\
\text { importantes para o tratamento. }\end{array}$ & $1 \mathrm{~h}$ \\
\hline $4-$ Jar Test & $\begin{array}{l}\text { Determinar a quantidade de alcalinizante e floculante para } \\
\text { remoção de partículas suspensas da água de captação. }\end{array}$ & $1 \mathrm{~h}$ \\
\hline $5-$ Oxigênio dissolvido & $\begin{array}{l}\text { Medir a quantidade de oxigênio dissolvido, parâmetro importante } \\
\text { para a avaliação do grau de poluição da água. }\end{array}$ & $1 \mathrm{~h}$ \\
\hline 6 - Biodiesel & Produzir o combustível a partir de óleo de cozinha usado e mini-usina. & $1 \mathrm{~h}$ \\
\hline & TOTAL & $6 \mathrm{~h}$ \\
\hline
\end{tabular}


Quadro 3: Conteúdo Programático do Curso de EA - Oficinas

\begin{tabular}{l|l|c}
\hline Aula & Objetivo & $\begin{array}{c}\text { Carga } \\
\text { Horária }\end{array}$ \\
\hline 1 - Educação Ambiental nas escolas & Trabalhar os conceitos de Agenda 21 nas escolas. & $4 \mathrm{~h}$ \\
\hline $\begin{array}{l}2-\text { Construção de projeto de feira de } \\
\text { ciências }\end{array}$ & $\begin{array}{l}\text { Ensinar aos profissionais como se elabora um projeto e suas } \\
\text { etapas de execução. }\end{array}$ & $4 \mathrm{~h}$ \\
\hline $\begin{array}{l}3-\text { Reaproveitamento de resíduos } \\
\text { sólidos }\end{array}$ & $\begin{array}{l}\text { Oficina de produção de equipamentos para aulas de ciências com } \\
\text { materiais recicláveis. }\end{array}$ & $4 \mathrm{~h}$ \\
\hline & TOTAL & $12 \mathrm{~h}$ \\
\hline
\end{tabular}

As turmas são abertas com 40 vagas e a divulgação é feita através do site da instituição (www. fat.uerj.br), tendo como público-alvo professores da educação básica e superior de qualquer área. A seleção é feita por ordem de inscrição. O curso é gratuito e somente há um taxa de inscrição para o material. Este recurso é gerido pelo CEPUERJ, assim como a inscrição.

No final do curso, o aluno é avaliado com uma prova individual escrita, com média mínima para a aprovação de 7,0 (sete). O diploma é expedido pela SR3 - UERJ.

Inicialmente foram somente abertas vagas para nível superior. Em razão da procura de grande número de profissionais de nível médio, no ano de 2009 foi disponibilizado o ingresso para o público deste segmento. O público-alvo do curso é muito diversificado. Com isso, os conteúdos abordados são devidamente adequados para que o aluno consiga acompanhar as aulas, seja qual for a sua formação.

Com mais de 100 profissionais formados pelo curso, cabe destacar que nos egressos estão incluídos cerca de 20 funcionários da Agência do Meio Ambiente de Resende e ex-presidentes da mesma agência.

No quadro 4 é mostrado o tipo de clientela que faz o curso.

Quadro 4: Tipo de clientela participante do curso.

\begin{tabular}{l|l|l}
\hline Ano & Áreas de Nível Superior & Nível Médio \\
\hline 2008 & $\begin{array}{l}\text { Química, Biologia, Geografia, Física, } \\
\text { Pedagogia, História, Biblioteconomia }\end{array}$ & \\
\hline \multirow{3}{*}{2009} & $\begin{array}{l}\text { Química, Biologia, Geografia,Física, } \\
\text { Administração, Engenharia Química, } \\
\text { Engenharia Civil, Pedagogia, } \\
\text { Comunicação Social e Direito }\end{array}$ & $\begin{array}{l}\text { Técnico Químico, Técnico em } \\
\text { Informática, Técnico em Meio } \\
\text { Ambiente }\end{array}$ \\
\hline \multirow{2}{*}{2010} & $\begin{array}{l}\text { Geografia, Administração, Engenharia } \\
\text { Química, Engenharia Sanitária } \\
\text { Pedagogia, Comunicação Social }\end{array}$ & $\begin{array}{l}\text { Técnico Química, Técnico em } \\
\text { Informática, Técnico em Meio } \\
\text { Ambiente }\end{array}$ \\
\hline
\end{tabular}

Os egressos do curso têm atuado como educadores ambientais nas escolas de origem ou nas prefeituras da região, difundindo os conhecimentos adquiridos no curso.

Os conhecimentos técnicos adquiridos pelos alunos são importantes, principalmente pelo fato de muitos educadores ambientais atuantes terem formação em diversas áreas diferentes da química e da física.
Um educador ambiental ou profissional equivalente necessita compreender os fenômenos químicos e físicos relacionados aos fenômenos ambientais, como efeito estufa e inversão térmica, para que possa efetivamente transmitir conhecimento à população. Neste contexto, consideramos o curso, com a matriz atual, importante nesta formação, pois reúne formação técnica, formação prática e oficinas de aplicação dos conhecimentos adquiridos. 


\section{Conclusões}

Durante o tempo em que o referido curso foi ministrado, verificou-se o atendimento à demanda da comunidade local; da mesma forma, observou-se o cumprimento da capacitação, ao proporcionar aos integrantes do curso condições de atuar como educadores ambientais ministrando conhecimentos básicos de Química Ambiental.

Enquanto projeto extencionista a capacitação proposta permite a interação da Universidade com a população local, a partir da difusão dos conhecimentos acadêmicos e de pesquisa.

Para a sociedade, o projeto é importante, pois contribui para a formação continuada dos profissionais da região, que podem atuar como multiplicadores dos conhecimentos e técnicas apreendidos das aulas.

\section{Contribuição dos autores}

A professora Denise Celeste Godoy de Andrade Rodrigues elaborou o texto da pesquisa bibliográfica.

A professora Elaine Ferreira Tôrres elaborou o texto da metodologia, reuniu dados informati- vos e formatou o artigo de acordo com as normas exigidas pela Revista.

\section{Referências}

1. JUNIOR, Arlindo Philippi; PELICIONI, M. Cecília Focesi. Educação Ambiental: Desenvolvimento de Cursos e Projetos. 2. ed. São Paulo: Universidade de São Paulo. Faculdade de Saúde Pública. Núcleo de Informações em Saúde Ambiental. Signus Editora, 349 p., 2002.

2. VASCONCELOS, Hedy Silva Ramos de; SANCHEZ, Celso; PICCININI, Claudia; RIBEIRO, Teresa. A Formação do Educador Ambiental: Reflexões sobre os Caminhos para a Construção e Delimitação de um Objeto de Pesquisa em Educação Ambiental. In: REUNIÃO NACIONAL DA ANPEd, 29 - Associação Nacional de Pós-Graduação e Pesquisa em Educação, 29. Disponível em: http://www.anped. org.br/reunioes/29ra/trabalhos/trabalho/GT22-2381-Int.pdf. Acesso em: 16 nov. 2011.

3. SANTOS, Cláudia Coelho; SORRENTINO, Marcos. Formação de Educadores Ambientais: Em Busca da Potência de Ação. Disponível em: www.teses.usp.br/teses/disponiveis/91/91131/.../Claudia_Santos.pdf. Acesso em: 17 nov. 2011.

4. RODRIGUES, Patrícia Silva. A Importância do conhecimento Químico para a Educação Ambiental. Disponível em: http://www.uftm.edu.br/upload/ensino/AVIposgraduacao090803125020.pdf. Acesso em: 17 nov. 2011.

5. CORTES JR, Lailton Passos; CORIO, Paola; FERNAN. DEZ, Carmen. Química Nova na Escola, v. 31, n. 1, 2009.

\begin{abstract}
This present paper intends to report the actions of enlarging an extension course, which unites Chemical Technology and Environmental Education offered annually to teachers of basic and higher education and the professionals who work in the environmental field, so that the concepts are highlighted relevant to the environment. The methodology used in the design and expansion of the course was based on anonymous satisfaction questionnaires applied to all participants. As a result, the current increased from 30 to $78 \mathrm{~h} /$ class. We can conclude that the course meets the demand of the region and has contributed to the qualification and continuous training of various professionals, since the graduates work in environmental agencies and local environmental education centers.
\end{abstract}

Keywords: Environmental Education; Sustainability; Empowering 